\title{
Attitudes, Barriers, and Concerns Regarding Telemedicine Among Swedish Primary Care Physicians: A Qualitative Study
}

\author{
Hanna Glock (D) \\ Veronica Milos Nymberg (D) \\ Beata Borgström Bolmsjö ii \\ Jonas Holm (iD) \\ Susanna Calling (D) \\ Moa Wolff iD \\ Miriam Pikkemaat (iD \\ Center for Primary Health Care \\ Research, Department of Clinical \\ Sciences in Malmö, Lund University, \\ Malmö, Sweden
}

Purpose: The primary care physician's traditional patient contacts are challenged by the rapidly accelerating digital transformation. In a quantitative survey analysis based on the theory of planned behavior, we found high behavioral intention to use telemedicine among Swedish primary care physicians, but low reported use. The aim of this study was to further examine the physicians' experiences regarding telemedicine, with a focus on possible explanations for the gap between intention and use, through analysis of the free-text comments supplied in the survey. Material and Methods: The material was collected through a web-based survey which was sent out to physicians at 160 primary health care centers in southern Sweden from May to August 2019. The survey covered four areas: general experiences of telemedicine, digital contacts, chronic disease monitoring with digital tools, and artificial intelligence. A total of 100 physicians submitted one or more free-text comments. These were analyzed using qualitative content analysis with an inductive approach.

Results: The primary care physicians expressed attitudes towards telemedicine that focused on clinical usefulness. Barriers to use were the loss of personal contact with patients and a deficient technological infrastructure. The major concerns were that these factors would result in patient harm and an increased workload. The connection between intention and use postulated by the theory of planned behavior was not applicable in this context, as external factors in the form of availability and clinical usefulness of the specific technology were major impediments to use despite a generally positive attitude.

Conclusion: All telemedicine tools must be evaluated regarding clinical usefulness, patient safety, and effects on staff workload, and end users should be included in this process. Utmost consideration is needed regarding how to retain the benefits of personal contact between patient and provider when digital solutions are introduced.

Keywords: eHealth, attitude of health personnel, general practitioners, survey

\section{Introduction}

\section{Background}

As defined by the Encyclopaedia Britannica, telemedicine is the "field in which telecommunication technologies and medicine interact to allow for the provision of health care remotely". ${ }^{1}$ However, the term telemedicine is often used to encompass all types of digital technologies in health care (also defined as eHealth), and that is how we use it in this paper. ${ }^{2}$ Telemedicine applications have increased rapidly in many parts of the world during the last decades. In Sweden, web-based psychiatric treatment, use of telemedicine for home-based treatment of chronically ill patients,
Correspondence: Hanna Glock

Research, Department of Clinical

Sciences in Malmö, Lund University,

Box 50332, Malmö, SE-202 I3, Sweden

Tel +46707979053

Email hanna.glock@med.lu.se 
and computerized clinical decision support systems (CDSS) to aid telephone triage were introduced during the $2000 \mathrm{~s}^{3-5}$ In the $2010 \mathrm{~s}$, video consultations between patients and physicians were evaluated in rural areas. ${ }^{6,7}$ During the second half of the decade, commercial nationwide services for eVisits (digital consultations between patient and provider through text or video) increased rapidly, followed by eVisits in public primary care. ${ }^{8,9}$ The digital transition has been further catalyzed by the Coronavirus disease 2019 (COVID-19) pandemic. $^{10}$

Regarding clinical outcomes, evidence indicates that telemedicine is at least as effective as face-to-face care across several mediums, diseases, and medical specialties including primary care. ${ }^{11-15}$ CDSS have been found to positively affect practitioner performance. ${ }^{16}$ Computerbased medical histories have been shown to be clinically relevant. ${ }^{17}$ However, for all areas, evidence of higher quality is needed. ${ }^{11-17}$ For artificial intelligence in primary care, clinical applications and research are under rapid development but also raise concerns. ${ }^{18-21}$

New digital environments can be challenging for patients and caregivers alike, requiring continuous learning and adjustment. ${ }^{22}$ Patient acceptance of telemedicine is generally high. ${ }^{11-14,23}$ Physician attitudes and experiences have been more mixed. ${ }^{11,12,24,25}$ Important areas for physician acceptance of telemedicine include perceived usefulness and ease of use, technical concerns, effects on workflow, and security issues. ${ }^{16,26-28}$ Studies in primary care are less numerous, but findings have been similar. ${ }^{29-32}$ Regarding experiences of Scandinavian primary care physicians (PCPs), research mainly concerns digital communication with patients through text or video. Findings include increased efficiency and more precise communication, but also reports of overuse, information overload, and misinterpretations. ${ }^{33-37}$

While most papers cover specific tools, PCPs' overall views and experiences of telemedicine have been little studied, and not at all in a Swedish context. Consequently, in 2019, we conducted a web-based survey regarding telemedicine among PCPs in southern Sweden. The survey included Likert items based on the Theory of planned behavior (TPB), and requests for free-text comments. ${ }^{38}$ According to the TPB, an individual's behavioral intention may be used as an approximation for actual behavior. Predictors for behavioral intention, and thus by extension for behavior, are attitudes, subjective norms, and perceived behavioral control. The TPB can be used to describe, predict, and alter behaviors.
Quantitative analyses of the survey items showed that attitudes and perceived behavioral control were strong predictors for intention to use all three studied domains of telemedicine: digital contacts, chronic disease monitoring with digital tools, and artificial intelligence. However, despite high behavioral intention, reported use was low. ${ }^{39}$ To improve implementation of telemedicine, we considered it vital to explore the reasons behind this discrepancy. As the free-text comments supplied in the web-based survey contained diverse information about the PCPs' experiences of telemedicine, a pertinent next step was to analyze these comments using a qualitative approach. The aim of this study was thus to further examine PCPs' experiences regarding telemedicine, with a focus on possible explanations for the gap between intention and reported use.

\section{Setting}

Sweden is divided into 21 self-governing administrative regions. Skåne and Kronoberg are two regions in southern Sweden with 1.6 million inhabitants distributed in cities and in more rural areas. ${ }^{40}$

The Swedish regions are responsible for providing health care to the population. The health care services are publicly funded but can be carried out by public or private providers. ${ }^{41}$ Which digital systems are used is at the discretion of the providers, as long as these adhere to existing regulations. This has resulted in a multitude of systems for electronic medical records, laboratory results, prescriptions, communication with patients, and decision support. A common problem is that the systems do not share information and do not communicate between them. However, there are also national digital systems for access to medical records and prescriptions, and a national decision support for primary care is under development. ${ }^{42-45}$

\section{Materials and Methods Design and Participants}

A web-based survey was designed based on the TPB with focus on four domains: general experiences of telemedicine, digital contacts, chronic disease monitoring with digital tools, and artificial intelligence. ${ }^{46}$ The survey consisted of a questionnaire with items assessed on a 7-point Likert scale, and requests for free-text comments, for each of the four domains (Table 1). The questionnaire, including the requests for free-text comments, was pilot tested among PCPs $(n=24)$ for face validity and relevance of 
Table I Requests for Free-Text Comments

Do you have any comments regarding the use of different contact methods?

Do you have any comments regarding the use of digital contact methods in the form of e-mail, chat, or SMS?

Do you have any comments regarding the use of digital contact methods in the form of video consultations?

Do you have any comments regarding the use of digital contact methods in patient care?

Do you have any comments regarding the use of digital tools for monitoring of chronic diseases?

Do you have any comments regarding the use of artificial intelligence in patient care?

items and wordings. The feedback from the pilot group lead to final changes in wordings. The comments of the expert group lead to minor changes in the questionnaire. ${ }^{39}$ Thereafter, from May to August 2019, PCPs at all primary health care centers (PHCCs) in the counties Skåne and Kronoberg in southern Sweden were invited to anonymously participate in the survey. This encompassed 90 public and 70 private PHCCs, with an approximate total number of 820 PCPs. An electronic link was sent by email using the electronic data-base manager REDCap, asking the PHCC administrators to forward the link to the PCPs. ${ }^{47}$ A reminder was sent after two weeks.

\section{Data Analysis}

All free-text comments were transferred verbatim to a text file.

As the research question was exploratory, the material was analyzed with qualitative content analysis inspired by Graneheim and Lundman, using an inductive approach. ${ }^{48}$ The text was read repeatedly, and then transferred into Microsoft Excel (2017) for analysis. Since the individual comments were usually short and concise, the process was simplified by direct coding of most of the meaning units, without further condensation. In a few cases, the individual comment was divided into two or three meaning units. Related meaning units were labelled with a code by one of the authors. The codes were sorted into subcategories. Several of the authors then triangulated the meaning units, codes, and subcategories, and grouped the subcategories into categories. Examples of coding and categorization are shown in Table 2. The categories were then combined into themes. The categories and themes were triangulated amongst all authors. At this level of analysis, we systematized the material with a focus on explaining the previously observed gap between behavioral intention to use and reported use of telemedicine among the PCPs, that deviated from what has been postulated by the TPB.

All authors are resident (HG) or specialists of family medicine and work as PCPs in the geographical area where the survey was conducted. The manuscript was prepared according to the Standards for Reporting Qualitative Research. ${ }^{49}$

\section{Ethics Approval and Informed Consent}

The Swedish Ethical Review Authority gave an advisory statement, confirming that according to the Swedish Ethical Review Act (SFS 2003:460) ethical vetting was not required for this type of study. The study used only anonymous data. We did not ask the participants about their own health or other sensitive topics. All participants that submitted a questionnaire provided an informed consent to participate in the study, including publication of anonymized responses.

\section{Results}

\section{Categories and Themes}

During the coding process twenty subcategories were found, which were grouped into six categories. From

Table 2 Examples of Coding and Categorization

\begin{tabular}{|l|l|l|}
\hline Meaning Unit & Code & Subcategory \\
\hline $\begin{array}{l}\text { As a general practitioner, I am a specialist in meeting patients, in } \\
\text { conversations with the patient, in seeing the whole picture and } \\
\text { I feel that the conversation and personal contact with the patient } \\
\text { is being phased out. }\end{array}$ & $\begin{array}{l}\text { Personal contact better } \\
\text { than digital } \\
\text { communication }\end{array}$ & $\begin{array}{l}\text { The value of the } \\
\text { multifaceted } \\
\text { personal meeting }\end{array}$ \\
\hline $\begin{array}{l}\text { External more advanced decision support is so far cumbersome, } \\
\text { time consuming, and therefore difficult to use. }\end{array}$ & $\begin{array}{l}\text { Existing decision support } \\
\text { systems still too difficult } \\
\text { to use }\end{array}$ & $\begin{array}{l}\text { Deficiencies in } \\
\text { existing technology }\end{array}$ \\
\hline
\end{tabular}


these categories, three themes emerged: attitudes, barriers, and concerns regarding telemedicine (Table 3). In the remainder of the Results section, we describe the material more in depth. Themes are signaled by headings, categories by subheadings, subcategories are marked in " ", and PCP quotations are presented in quotation format.

\section{Attitudes}

\section{Different Opinions Among Physicians}

Several PCPs expressed a generally "positive" attitude towards increased digitalization, in some instances bordering to impatience.

Long awaited!!! Enormous resource that must become available in health care.

More specifically, there were thoughts that telemedicine would simplify the PCP's work, increase patient empowerment, and result in improved medical care.

Stands for development and modernization of primary care.
A few PCPs expressed a generally "skeptical" attitude, which may be exemplified by the following comment:

The emperor's new clothes.

\section{Useful Under Certain Conditions}

Many PCPs thought that telemedicine could be "suitable for some patients, complaints, and requests". It was pointed out that the patients first needed access to and ability to use the new technology.

Could be useful for some patients, but one should not take for granted that all patients would be able to handle it. Rather the other way around. It requires computer/smartphone, sufficient cognitive functions, and engagement.

Some saw it as a prerequisite that the PCP had prior knowledge of the patient. Regarding appropriate types of complaints, the PCPs mentioned skin disorders and follow-up of mental illness. Doubts were raised about handling of more complicated or urgent complaints through text or video. Simple requests such as scheduling of visits or information about laboratory results were put forth as

Table 3 Subcategories, Categories, and Themes

\begin{tabular}{|c|c|c|}
\hline Subcategory & Category & Theme \\
\hline $\begin{array}{l}\text { Positive physician } \\
\text { Skeptical physician }\end{array}$ & Different opinions among physicians & \multirow[t]{2}{*}{ Attitudes } \\
\hline $\begin{array}{l}\text { Suitable for some patients, complaints, and requests } \\
\text { Use must be voluntary } \\
\text { Need for evaluation }\end{array}$ & Useful under certain conditions & \\
\hline The value of the multifaceted personal meeting & The value of the multifaceted personal meeting & \multirow[t]{2}{*}{ Barriers } \\
\hline $\begin{array}{l}\text { Deficiencies in existing technology/technology is not available } \\
\text { Too little experience } \\
\text { Limitations put by laws or guidelines }\end{array}$ & Challenges due to a deficient technological infrastructure & \\
\hline $\begin{array}{l}\text { Deficient information security } \\
\text { Risk for patient harm } \\
\text { Increased risk of misunderstandings } \\
\text { Increased health care disparities }\end{array}$ & Risks for the patients & \multirow[t]{2}{*}{ Concerns } \\
\hline $\begin{array}{l}\text { The physician's integrity } \\
\text { Stressful time-thief } \\
\text { Additional work } \\
\text { Too many patient access routes } \\
\text { Too high accessibility } \\
\text { No added value } \\
\text { The professional perspective is missing }\end{array}$ & Risks for the profession & \\
\hline
\end{tabular}


suitable for digital contacts. A few PCPs further underlined that "use must be voluntary", and that digitalization must take place on the patients' terms.

It depends on the patient. The patient must feel as safe as possible. If that is the case, I will gladly use more digital tools etc.

The "need for evaluation" was put forth, through scientific research as well as through systematic quality improvement.

If more digital tools are to be introduced, those and all other digitalization must be slimmed to a minimum and evaluated to see if it benefits primarily the patient and secondly the healthcare providers.

\section{Barriers}

The Value of the Multifaceted Personal Meeting In different ways, the PCPs emphasized "the value of the multifaceted personal meeting" with the patient at the PHCC, and that this could not be replaced by digital communication.

As a general practitioner, I am a specialist in meeting patients, in conversations with the patient, in seeing the whole picture, and I feel that the conversation and personal contact with the patient is being phased out.

The PCPs described a relationship based on trust, with the physical meeting providing the most beneficial conditions to see the whole person and their problems. This was especially important for multimorbid patients, who were considered difficult to assess in other ways.

The personal meeting gives you the opportunity to assess all modalities, not only image and speech but also much more discreet things... such as moods, scents, etc.

The importance of body language and all the information it provides was emphasized. The PCPs expressed that the risk of misunderstandings decreased when they could look and listen for nuances in the patient's way of reacting to information and diagnosis.

\section{Challenges Due to a Deficient Technological Infrastructure}

Several PCPs provided examples of "deficiencies in existing technology". They described that the technology was often hard to work with, as the digital systems were not integrated with the electronic medical record. This frequently meant double documentation and timeconsuming changes between the different systems.

External more advanced decision support is so far cumbersome, time-consuming, and therefore difficult to use.

It was emphasized that the patients also must have access to functional technology, meeting the same requirements for reliability as other medical devices. Although many physicians reported that appropriate "technology was not available", they expressed hope for welldeveloped systems in the future.

First, we need better digital tools that are better adapted to the needs of patients and healthcare providers ...

Several physicians considered themselves to have "too little experience" of working with digital communication to be able to answer the questionnaire. It was also pointed out that there were "limitations put by laws or guidelines" regarding some forms of digital communication due to information security issues.

No function that is safe enough and encrypted is available for our e-mail.

\section{Concerns}

\section{Risks for the Patients}

The PCPs identified several risks for patients when using telemedicine. One concern was "deficient information security" in the existing systems. There were also concerns that medical assessments via digital contacts would increase the "risk for patient harm".

\section{In addition, the digital forms are not completely ready and the damage to the patient is large. We 'drive the car while we build it', and it does not feel good considering that it is patients that we take care of and not any 'nails' that we can discard of if things go wrong.}

Some feared that untriaged new contact routes would cause a delay for cases that may require urgent medical treatment. Concerns were also raised that blood pressure monitoring or continuous reporting of blood glucose levels could provide a false sense of security unless time was set aside for the PCP to properly follow up on the results.

Just because one can control, measure, monitor, and sign off on results infinitely, it does not mean that the patient benefits. Rather the opposite. 
A few PCPs also described an "increased risk of misunderstandings" when using chat conversations, and of incorrect diagnoses when using video consultations, as compared to physical contact. Others meant that digitalization could cause "increased healthcare disparities".

Health care becomes too easily accessible. Only minor ailments can be dealt with. Because health care resources are insufficient, this contact method takes resources from those who need it better.

Several physicians emphasized that there would be a weaker group of patients that would be left behind, namely the elderly and often multimorbid.

\section{Risks for the Profession}

Some physicians expressed concerns about their own "integrity" when using video consultations.

Extremely uncomfortable even though I have nothing to hide. I do not want my conversation/examination with the patient to be at risk of being saved and used against me or the patient later. Violation of integrity. No systems are secure and what one has said in one context can be given a very skewed angle when taken out of its context...

A recurringly described risk with digitalization was that it easily becomes a "stressful time-thief". It was put forth that new technology often resulted in "additional work".

Digital contacts end up on top of the traditional ones, without a medically adequate allocation of time or resources.

Consequently, as things stand, it becomes a stressor.

The physicians did not experience that time was set aside for digital communication in their often already full schedule. Concerns were also raised regarding an increasing amount of information in the form of digitally obtained measurements, and the difficulty to screen unselected data in a short amount of time.

More information is not the same thing as better health care.

Higher flow of information can paradoxically lead to worse decisions, stress, and that you cannot see the forest for the trees.

The stress factor was further highlighted in comments about risks with "too many patient access routes" and "too high accessibility". The physicians described reduced overview and time-consuming switches between systems. They saw a risk that there would be less time to meet patients in person.
Table 4 Characteristics of the Respondents Who Submitted Free-Text Comments $(\mathrm{N}=100)$

\begin{tabular}{|l|l|}
\hline Characteristic & Mean (SD) \\
\hline Age in years & $47(\mathrm{II})$ \\
Years of experience in primary care & I3 (9) \\
\hline Characteristic & Participants, $\mathbf{n}$ \\
\hline Sex, male & 47 \\
Sex, female & $5 \mathrm{I}$ \\
Sex, not defined & 2 \\
Specialist of family medicine & 66 \\
Resident of family medicine & 27 \\
Intern or other assistant physician & 3 \\
Other specialist & 3 \\
Specialty missing & $\mathrm{I}$ \\
Public primary care workplace & $8 \mathrm{I}$ \\
Private primary care workplace & 18 \\
Workplace missing & $\mathrm{I}$ \\
\hline
\end{tabular}

You should not have too many patient access routes. It will be stressful and unmanageable.

Several physicians did not see that the new technology facilitated their work. Put differently, they experienced "no added value" from telemedicine.

Everything is put on top without anything being taken away, which makes this just one more thing. It has not provided relief anywhere else in the system.

Lastly, a few physicians brought up that the "professional perspective was missing".

I think that too little consideration is given to the purely professional aspects of this. It is too much about access and who shouts the loudest, in combination with administrators who believe themselves to be able to assess things that they have no knowledge about.

\section{Participant Characteristics}

A total of 198 questionnaires were received from the 820 physicians (response rate 24\%), and 100 physicians had written at least one free-text comment (response rate 12\%). Characteristics of the respondents who submitted free-text comments are summarized in Table 4.

\section{Discussion}

\section{Main Findings}

In this web-based survey, PCPs in southern Sweden expressed attitudes towards telemedicine that focused on 
clinical usefulness. Barriers to use were the loss of personal contact with patients and a deficient technological infrastructure. The major concerns were that these factors would result in patient harm and an increased workload.

In agreement with the high intention to use telemedicine found in the previous quantitative analysis of PCP survey responses, this qualitative analysis of free-text comments also showed that the general attitudes towards digital solutions among the PCPs were positive. ${ }^{39}$ However, this was under the provision that the specific solutions were clinically useful. At the time of the survey, barriers in the form of low availability and technology that was not adapted to the needs of primary health care, and concerns regarding risks primarily due to insufficient clinical evaluation, appeared as major reasons for the low reported use of telemedicine. Thus, the connection between intention and use postulated by the TPB was not applicable in this context, as external factors in the form of availability and clinical usefulness of the specific technology were major impediments to use despite a generally positive attitude. Shifting the perspective, an explanation for the high intention to use telemedicine despite barriers and concerns may be the hope of a more clinically useful technology, as lined out by the subcategories "positive physician" and "useful under certain conditions".

\section{Strengths and Limitations}

A weakness of this study was the lack of purposive sampling despite a qualitative approach. The low response rate of $12 \%$ for the free text comments was a further limitation. Low response rates are a common issue for PCP surveys and even more so for web-based ones. ${ }^{50}$ However, it has been shown that web-based surveys are as reliable as paper-based surveys. ${ }^{51}$ Further, the survey format made it possible to include a large number of physicians. The resulting respondent characteristics were varied with regard to gender, age, years of experience, and workplace (Table 4). Comments covered a wide range from positive to negative, centered on some common themes, and were in accordance with prior research. ${ }^{12,29}$ This indicates that the self-selected respondents were representative, that saturation was reached, and that the results may be transferable to similar settings. Thus, the amount and variability of comments partially compensated for the lack of purposive sampling. In addition, the full anonymity of participants minimized the social influence that would have been a limitation in interviews or focus groups.

\section{Comparison with Other Studies}

The views expressed in this survey were similar to those described in previous research regarding staff experience of telemedicine, with major importance being put on clinical usefulness, technical concerns, and workload issues. ${ }^{16,26-30}$ This study adds a more distinct focus on the loss of personal contact with patients, or in other words "the value of the multifaceted personal meeting". Traditional primary care work includes assessing the patient with the help of experience and through all senses. Consultation methods in primary care, such as the "five cards" that is taught in Sweden, aim to facilitate understanding and trust between patient and physician. ${ }^{52}$ Digital filters may compromise these processes. Thus, caution must be taken not to impair on the diagnostic process nor the patient-physician relationship but rather to add to it.

Focusing on the context of Swedish primary care, three different studies recently found that physicians considered the types of telemedicine evaluated to be suitable for some patients and questions, but not for all. ${ }^{35-37}$ This compares well to our category "Useful under certain conditions", underlining the need for implementation in cooperation with the profession.

The survey was conducted before the COVID-19 pandemic. It is thus interesting to see how our results compare to studies undertaken during the pandemic. In the United States, physicians expressed concerns regarding the loss of physical examination and personal connection, and effects on workload. ${ }^{31}$ Physicians in the United Kingdom (UK) raised warnings about increased clinical risks. ${ }^{32}$ The majority of UK PCPs were satisfied with video visits, but also had felt that video was not appropriate in some instances. ${ }^{53}$ Thus, views expressed in our survey seem transferable to the context of the pandemic. A possible explanation for this is that the basic conditions of primary care remain relatively unchanged, even if digitalization increases. If so, our findings should also be transferable to primary care after the pandemic.

\section{Conclusion}

To improve clinical usefulness of telemedicine, PCP concerns should be more thoroughly addressed. All telemedicine tools and solutions must be evaluated regarding clinical usefulness, patient safety, and effects on staff workload, and end users should be included in this process. Utmost consideration is needed regarding how to 
retain the benefits of personal contact between patient and provider when digital solutions are introduced.

\section{Abbreviations}

CDSS, clinical decision support systems; COVID-19, Coronavirus disease 2019; PCP, primary care physician; PHCC, primary health care center; TPB, theory of planned behavior; UK, United Kingdom.

\section{Data Sharing Statement}

The data files (free-text comments and categorized material) generated during this study are available from the corresponding author upon reasonable request.

\section{Author Contributions}

All authors made a significant contribution to the work reported, whether that is in the conception, study design, execution, acquisition of data, analysis and interpretation, or in all these areas; took part in drafting, revising or critically reviewing the article; gave final approval of the version to be published; have agreed on the journal to which the article has been submitted; and agree to be accountable for all aspects of the work.

\section{Funding}

The study was supported by ALF funding from Region Skåne awarded to Susanna Calling. The authors received no other financial support for the research or authorship of this article.

\section{Disclosure}

The authors report no conflicts of interest in this work.

\section{References}

1. Encyclopaedia Britannica. Telemedicine; 2013. Available from: https:// www.britannica.com/science/telemedicine. Accessed July 9, 2021.

2. Encyclopaedia Britannica. E-health; 2013. Available from: https:// www.britannica.com/science/e-health. Accessed July 9, 2021.

3. Andersson G. Using the Internet to provide cognitive behaviour therapy. Behav Res Ther. 2009;47(3):175-180. doi:10.1016/j. brat.2009.01.010

4. Olsson S, Jarlman O. A short overview of eHealth in Sweden. Int J Circumpolar Health. 2004;63(4):317-321. doi:10.3402/ijch. v63i4. 17748

5. Holmstrom I. Decision aid software programs in telenursing: not used as intended? Experiences of Swedish telenurses. Nurs Health Sci. 2007;9(1):23-28. doi:10.1111/j.1442-2018.2007.00299.x

6. Johansson AM, Lindberg I, Soderberg S. The views of health-care personnel about video consultation prior to implementation in primary health care in rural areas. Prim Health Care Res Dev. 2014;15 (2):170-179. doi:10.1017/S1463423613000030
7. Johansson AM, Lindberg I, Soderberg S. Healthcare personnel's experiences using video consultation in primary healthcare in rural areas. Prim Health Care Res Dev. 2017;18(1):73-83. doi:10.1017/ S1463423616000347

8. Ekman B, Thulesius H, Wilkens J, Lindgren A, Cronberg O, Arvidsson E. Utilization of digital primary care in Sweden: descriptive analysis of claims data on demographics, socioeconomics, and diagnoses. Int $J$ Med Inform. 2019;127:134-140. doi:10.1016/j. ijmedinf.2019.04.016

9. Eldh AC, Sverker A, Bendtsen P, Nilsson E. Health Care Professionals' Experience of a Digital Tool for Patient Exchange, Anamnesis, and Triage in Primary Care: qualitative Study. JMIR Hum Factors. 2020;7(4):e21698. doi:10.2196/21698

10. Bitar H, Alismail S. The role of eHealth, telehealth, and telemedicine for chronic disease patients during COVID-19 pandemic: a rapid systematic review. Digit Health. 2021;7:20552076211009396. doi:10.1177/20552076211009396

11. Bashshur RL, Howell JD, Krupinski EA, Harms KM, Bashshur N, Doarn CR. The Empirical Foundations of Telemedicine Interventions in Primary Care. Telemed $J$ E Health. 2016;22(5):342-375. doi: $10.1089 / \mathrm{tmj} .2016 .0045$

12. Mold F, Hendy J, Lai YL, de Lusignan S. Electronic Consultation in Primary Care Between Providers and Patients: systematic Review. JMIR Med Inform. 2019;7(4):e13042. doi:10.2196/13042

13. Eze ND, Mateus C, Cravo Oliveira Hashiguchi T. Telemedicine in the OECD: an umbrella review of clinical and cost-effectiveness, patient experience and implementation. PLoS One. 2020;15(8):e237585. doi:10.1371/journal.pone.0237585

14. Haveland S, Islam S. Key considerations in ensuring a safe regional telehealth care model: a systematic review. Telemed J E Health. 2021. doi: $10.1089 / \mathrm{tmj} .2020 .0580$

15. Nguyen OT, Alishahi Tabriz A, Huo J, Hanna K, Shea CM, Turner K. Impact of asynchronous electronic communication-based visits on clinical outcomes and health care delivery: systematic review. J Med Internet Res. 2021;23(5):e27531. doi:10.2196/27531

16. Kruse CS, Ehrbar N. Effects of computerized decision support systems on practitioner performance and patient outcomes: systematic review. JMIR Med Inform. 2020;8(8):e17283. doi:10.2196/17283

17. Zakim D. Development and significance of automated history-taking software for clinical medicine, clinical research and basic medical science. J Intern Med. 2016;280(3):287-299. doi:10.1111/joim.12509

18. Kueper JK, Terry AL, Zwarenstein M, Lizotte DJ. Artificial intelligence and primary care research: a scoping review. Ann Fam Med. 2020;18(3):250-258. doi:10.1370/afm.2518

19. Liyanage H, Liaw ST, Jonnagaddala J, et al. Artificial Intelligence in Primary Health Care: perceptions, Issues, and Challenges. Yearb Med Inform. 2019;28(1):41-46. doi:10.1055/s-0039-1677901

20. Spanig S, Emberger-Klein A, Sowa JP, Canbay A, Menrad K, Heider D. The virtual doctor: an interactive clinical-decisionsupport system based on deep learning for non-invasive prediction of diabetes. Artif Intell Med. 2019;100:101706. doi:10.1016/j. artmed.2019.101706

21. Lee H, Kang J, Yeo J. Medical specialty recommendations by an artificial intelligence chatbot on a smartphone: development and deployment. J Med Internet Res. 2021;23(5):e27460. doi:10.2196/27460

22. Nymberg VM, Bolmsjo BB, Wolff M, Calling S, Gerward S, Sandberg M. 'Having to learn this so late in our lives ...' Swedish elderly patients' beliefs, experiences, attitudes and expectations of e-health in primary health care. Scand J Prim Health Care. 2019;37 (1):41-52. doi:10.1080/02813432.2019.1570612

23. Gabrielsson-Jarhult F, Kjellstrom S, Josefsson KA. Telemedicine consultations with physicians in Swedish primary care: a mixed methods study of users' experiences and care patterns. Scand $J$ Prim Health Care. 2021;1-10. doi:10.1080/02813432.20 21.1913904 
24. Ross J, Stevenson F, Lau R, Murray E. Factors that influence the implementation of e-health: a systematic review of systematic reviews (an update). Implement Sci. 2016;11(1):146. doi:10.1186/ s13012-016-0510-7

25. Jacob C, Sanchez-Vazquez A, Ivory C. Social, organizational, and technological factors impacting clinicians' adoption of mobile health tools: systematic literature review. JMIR Mhealth Uhealth. 2020;8(2): e15935. doi:10.2196/15935

26. Gagnon MP, Desmartis M, Labrecque M, et al. Systematic review of factors influencing the adoption of information and communication technologies by healthcare professionals. J Med Syst. 2012;36 (1):241-277. doi:10.1007/s10916-010-9473-4

27. Gagnon MP, Ngangue P, Payne-Gagnon J, Desmartis M. m-Health adoption by healthcare professionals: a systematic review. J Am Med Inform Assoc. 2016;23(1):212-220. doi:10.1093/jamia/ocv052

28. Khairat S, Marc D, Crosby W, Al Sanousi A. Reasons for physicians not adopting clinical decision support systems: critical analysis. JMIR Med Inform. 2018;6(2):e24. doi:10.2196/medinform.8912

29. Davis MM, Freeman M, Kaye J, Vuckovic N, Buckley DI. A systematic review of clinician and staff views on the acceptability of incorporating remote monitoring technology into primary care. Telemed J E Health. 2014;20(5):428-438. doi:10.1089/tmj.2013.0166

30. Salisbury C, Murphy M, Duncan P. The Impact of Digital-First Consultations on Workload in General Practice: modeling Study. J Med Internet Res. 2020;22(6):e18203. doi:10.2196/18203

31. Gomez T, Anaya YB, Shih KJ, Tarn DM. A qualitative study of primary care physicians' experiences with telemedicine during COVID-19. J Am Board Fam Med. 2021;34(Suppl):S61-S70. doi:10.3122/jabfm.2021.S1.200517

32. Murphy M, Scott LJ, Salisbury C, et al. Implementation of remote consulting in UK primary care following the COVID-19 pandemic: a mixed-methods longitudinal study. Br J Gen Pract. 2021;71(704): e166-e177. doi:10.3399/BJGP.2020.0948

33. Fagerlund AJ, Holm IM, Zanaboni P. General practitioners' perceptions towards the use of digital health services for citizens in primary care: a qualitative interview study. BMJ Open. 2019;9(5):e028251. doi:10.1136/bmjopen-2018-028251

34. Gronning A, Assing Hvidt E, Nisbeth Brogger M, Fage-Butler A. How do patients and general practitioners in Denmark perceive the communicative advantages and disadvantages of access via email consultations? A media-theoretical qualitative study. BMJ Open. 2020;10(10):e039442. doi:10.1136/bmjopen-2020-039442

35. Bjorndell C, Premberg A. Physicians' experiences of video consultation with patients at a public virtual primary care clinic: a qualitative interview study. Scand J Prim Health Care. 2021;39(1):67-76. doi:10.1080/02813432.2021.1882082

36. Johansson A, Larsson M, Ivarsson B. General Practitioners' Experiences of Digital Written Patient Dialogues: a Pilot Study Using a Mixed Method. J Prim Care Community Health. 2020;11:2150132720909656. doi:10.1177/2150132720909656

37. Entezarjou A, Bolmsjo BB, Calling S, Midlov P, Milos nymberg V. Experiences of digital communication with automated patient interviews and asynchronous chat in Swedish primary care: a qualitative study. BMJ Open. 2020;10(7):e036585. doi:10.1136/bmjopen-2019-036585

38. Ajzen I. The theory of planned behavior. Organ Behav Hum Decis Process. 1991;50(2):179-211. doi:10.1016/0749-5978(91)90020-T

39. Pikkemaat M, Thulesius H, Milos Nymberg V. Swedish Primary Care Physicians' Intentions to Use Telemedicine: a Survey Using a New Questionnaire - Physician Attitudes and Intentions to Use Telemedicine (PAIT). Int $J$ Gen Med. 2021;14:3445-3455. doi:10.2147/IJGM.S319497
40. Statistics Sweden. Available from: https://www.statistikdatabasen. scb.se/. Accessed September 9, 2021.

41. Swedish Institute. Healthcare in Sweden; 2021. Available from: https:// sweden.se/life/society/healthcare-in-sweden. Accessed September 9, 2021.

42. Swedish Ministry of Health and Social Affairs. Vision for e-health 2025 - common starting points for digitalisation of social services and health care. S2016.012; 2016. Available from: https:/ehalsa2025.se/ wp-content/uploads/2021/02/vision-for-ehealth-2025.pdf. Accessed September 18, 2021.

43. Swedish Ministry of Health and Social Affairs. Vision for e-health 2025: follow-up 2019; 2020. Available from: https://ehalsa2025.se/ wp-content/uploads/2021/02/Follow-up-2019_Vision-e-health-2025. pdf. Accessed September 18, 2021.

44. Stiernstedt G, Zetterberg D, Stjernquist A, Elgán C Digi-physical patient care choice - Accessible primary care based on need and continuity. SoU 2019:42. Swedish Ministry of Health and Social Affairs; 2019. Available from: https://www.regeringen.se/4ad5e9/con tentassets/6e378658462844798630946d5bf12fc3/digifysiskt-vardval -_tillganglig-primarvard-baserad-pa-behov-och-kontinuitet.pdf. Accessed March 17, 2021.

45. Persson J, Rydenfalt C. Why Are Digital Health Care Systems Still Poorly Designed, and Why Is Health Care Practice Not Asking for More? Three Paths Toward a Sustainable Digital Work Environment. J Med Internet Res. 2021;23(6):e26694. doi:10.2196/26694

46. Francis J. Constructing Questionnaires Based on the Theory of Planned Behaviour: A Manual for Health Services Researchers. 2004.

47. Harris PA, Taylor R, Thielke R, Payne J, Gonzalez N, Conde JG. Research electronic data capture (REDCap)-a metadata-driven methodology and workflow process for providing translational research informatics support. $J$ Biomed Inform. 2009;42(2):377-381. doi:10.1016/j.jbi.2008.08.010

48. Graneheim UH, Lundman B. Qualitative content analysis in nursing research: concepts, procedures and measures to achieve trustworthiness. Nurse Educ Today. 2004;24(2):105-112. doi:10.1016/j.nedt.2003.10.001

49. O'Brien BC, Harris IB, Beckman TJ, Reed DA, Cook DA. Standards for reporting qualitative research: a synthesis of recommendations. Acad Med. 2014;89(9):1245-1251. doi:10.1097/ACM.0000000000000388

50. Pit SW, Vo T, Pyakurel S. The effectiveness of recruitment strategies on general practitioner's survey response rates - A systematic review. BMC Med Res Methodol. 2014;14:76. doi:10.1186/1471-2288-14-76

51. Ritter P, Lorig K, Laurent D, Matthews K. Internet versus mailed questionnaires: a randomized comparison. J Med Internet Res. 2004;6 (3):e29. doi:10.2196/jmir.6.3.e29

52. Larsen JH, Neighbour R. Five cards: a simple guide to beginning the consultation. Br J Gen Pract. 2014;64(620):150-151. doi:10.3399/ bjgp14X677662

53. Gold KJ, Laurie AR, Kinney DR, Harmes KM, Serlin DC. Video Visits: family Physician Experiences With Uptake During the COVID-19 Pandemic. Fam Med. 2021;53(3):207-210. doi:10.22454/FamMed.2021.613099 


\section{Publish your work in this journal}

The International Journal of General Medicine is an international, peer-reviewed open-access journal that focuses on general and internal medicine, pathogenesis, epidemiology, diagnosis, monitoring and treatment protocols. The journal is characterized by the rapid reporting of reviews, original research and clinical studies across all disease areas. The manuscript management system is completely online and includes a very quick and fair peer-review system, which is all easy to use. Visit http://www.dovepress.com/ testimonials.php to read real quotes from published authors.

Submit your manuscript here: https://www.dovepress.com/international-journal-of-general-medicine-journal 